\title{
Surgical resection with autologous microvascular reconstruction of the mandible conferring excellent cosmesis and prognosis in ameloblastoma
}

\author{
Harish Kumar H ${ }^{1, *}$, Raghunandan G.C ${ }^{2}$, Sunder Raj Ellur ${ }^{3}$, Rakesh S Ramesh ${ }^{4}$, Diviya K Kariappa ${ }^{5}$ \\ ${ }^{1,2}$ Assistant Professor, ${ }^{3}$ Professor, ${ }^{\mathbf{4}}$ Associate Professor, ${ }^{\mathbf{5}}$ M.ch Resident, Dept. of Surgical Oncology, St. Johns Medical College Hospital, \\ Bengaluru, Karnataka, India
}

*Corresponding Author: Harish Kumar H

Email: harishkumarh1983@gmail.com

\begin{abstract}
Ameloblastoma is a benign odontogenic tumor generally present in the jaw bone. The purpose of this study was to evaluate the clinicopathological profile, treatment and its outcome in a consecutive case series of 8 cases involving mandible and also other tumor like conditions of mandible mimicking ameloblastoma. A total of 10 patients were treated over period of 4 years, which were retrospectively reviewed in our institution. Imaging (CT scan) was done in all the cases and Biopsy was done in 9 cases. Of the 10 patients, 6 males and 4 females were identified. The average age was 25.1 years (range 7-46 years). Swelling in the region of mandible was the only complaint in all the patients. Segmental mandibulectomy was done with free fibular graft was done in 8 cases, Hemimandibulectomy without reconstruction was done in one case and reconstruction with titanium plate was done in another case. All patients underwent grossly complete surgical removal of the lesions, and no recurrence occurred during the follow-up period. The clinical profile and outcome may provide some insights into the differential diagnosis and clinical management. The best treatment option available is surgical excision with either autologous graft or prosthetic implant which can result in a good prognosis and cosmesis.
\end{abstract}

Keywords: Ameloblastoma, Mandible, Segmental mandibulectomy, Free fibula flap.

\section{Introduction}

Ameloblastoma, is derived from the English word "amel" which means enamel and the Greek word "blastos" which means the germ. ${ }^{1}$ It arises from the epithelium of the dental lamina, characterized by local aggressive behavior and high recurrence rate. Ameloblastoma was first described by Cusack. in $1827 . .^{2}$ The term ameloblastoma was coined in 1930 by Ivey and Churchill. ${ }^{3,4}$ The World Health Organization in 1991 defined ameloblastoma as a benign but locally aggressive tumor with a high tendency to recur, consisting of proliferating odontogenic epithelium lying in a fibrous stroma. Both benign and malignant variants have been described in the classification proposed by WHO for odontogenic tumors of mandible. Its variants include unicystic ameloblastoma, desmoplastic ameloblastoma and keratoameloblastoma, among which unicystic has different behavior and hence prognosis. ${ }^{5}$ Unicystic ameloblastoma in particular refers to those cystic lesions that show radiologic and clinical behaviour of an odontogenic cyst, but on histological examination, shows a typical ameloblastomatous epithelium lining part of the cyst cavity, with or without luminal and/or mural tumor proliferation. ${ }^{6}$ Gorlin et a1., ${ }^{7}$ and Hinds et al., ${ }^{8}$ have summarized the following as the possible sources of origin i.e., epithelial lining of an odontogenic cyst stratified squamous epithelium of the oral cavity, dental lamina or enamel organ, displaced dental epithelial remnants. Accounts for about $1 \%$ of odontogenic tumors and cysts. Their etiology is unknown and the majority develops without an apparent cause. ${ }^{9}$ This entity should not be confused with the term adamantinoma, as both differ in frequency of malignancy and histology.

\section{Materials and Methods}

Table 1: Clinico-pathological profile and surgical management

\begin{tabular}{|l|c|c|c|c|c|c|c|}
\hline S. No. & $\begin{array}{c}\text { Age } \\
\text { (years) }\end{array}$ & Sex & Site & Size(cm) & HPR & Sx & Reconstruction \\
\hline 1 & 15 & M & Body & $3.5 \times 2.5$ & Hemangiomatous ameloblastoma & SM & A \\
\hline 2 & 46 & M & Body+Angle & $4 \times 4.5$ & Ameloblastoma (solid type) & SM & A \\
\hline 3 & 24 & M & Body+ Angle & $2.6 \times 1.5$ & Ameloblastoma & SM & A \\
\hline 4 & 24 & F & Body+ Angle & & Ameloblastoma(granular type) & SM & A \\
\hline 5 & 7 & M & Central/mentum & $2.6 \times 1.9$ & Benign angiomatous lesion & SM & A \\
\hline 6 & 16 & F & Body & $2.3 \times 2.2$ & Ameloblastoma & SM & A \\
\hline 7 & 24 & F & Para symphyseal & $3 \times 2.8$ & Cementing ossifying fibroma & SM & A \\
\hline 8 & 33 & F & Body & $2.5 \times 2$. & Ameloblastoma & SM & A \\
\hline 9 & 27 & F & Body+Ascending rami & $5 \times 4.5$ & Ameloblastoma & HM & Not done \\
\hline 10 & 35 & F & Body & $4.3 \times 3.4$ & Ameloblastoma & SM & B \\
\hline
\end{tabular}

M- Male SM- Segmental mandibulectomy A- Free fibular graft Sx-Surgery

F- Female HM- Hemimandibulectomy B- Titanium plate only 
In 8 patients, atleast $1 \mathrm{~cm}$ grossly negative margin was given and in 2 cases, atleast 5 m.m. grossly negative margin was given, of which margins were involved microscopically in those 2 cases.

\section{Images of representative cases:}

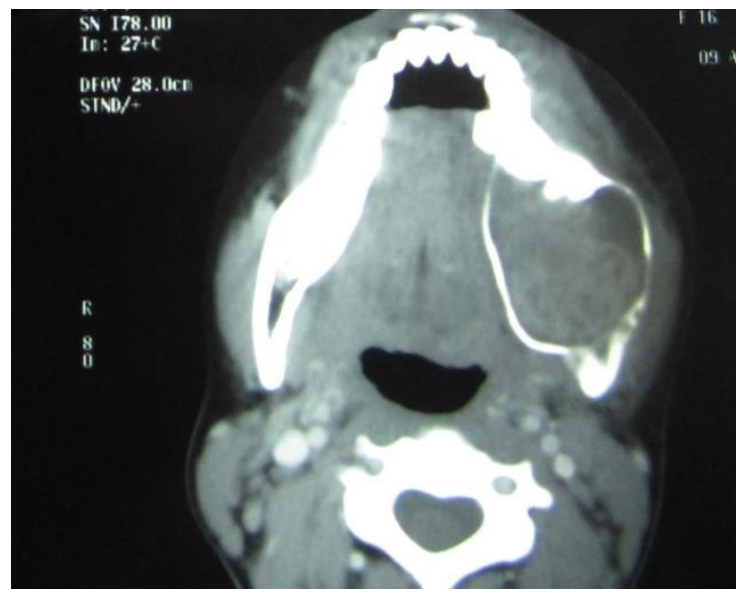

Fig. 1: Preoperative CT scan image of mandibular lesion

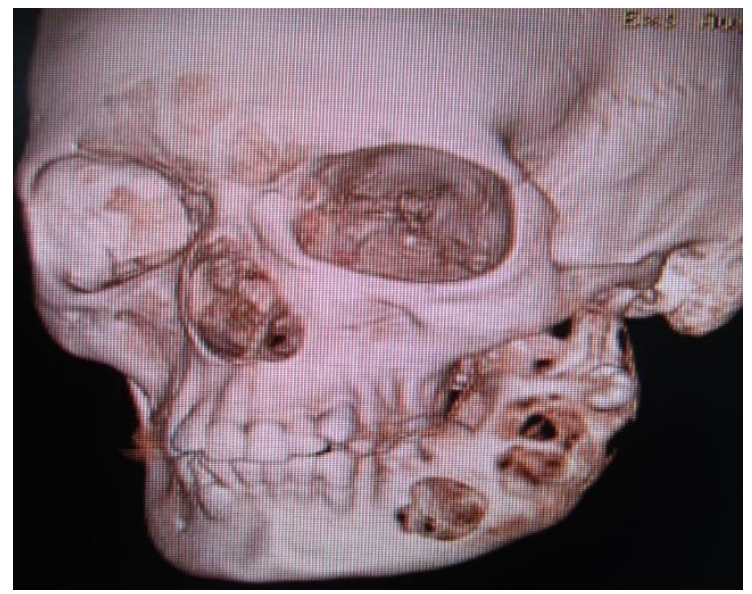

Fig. 2: CT scan with 3 D reconstruction showing the clear extent of lesion

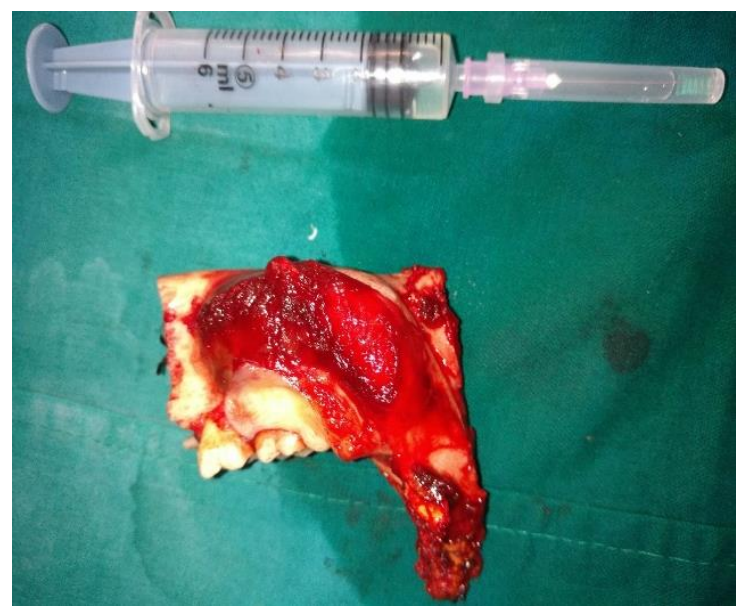

Fig. 3: Specimen photograph

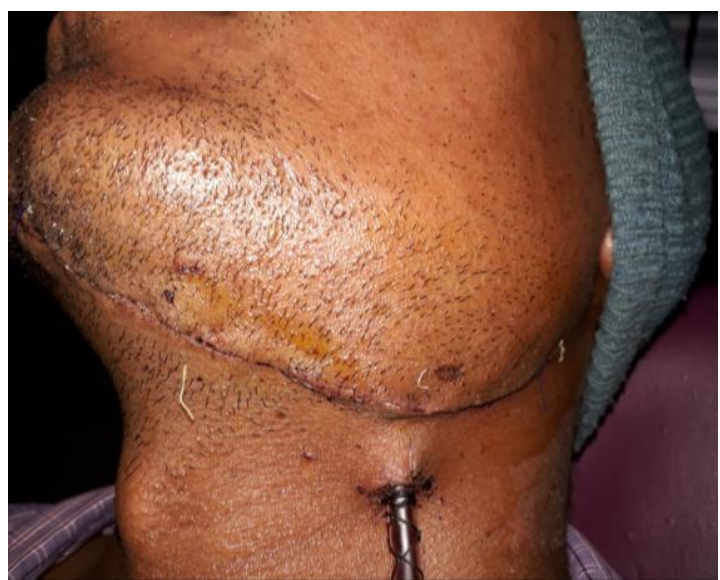

Fig. 4: Postoperative day 3 photograph

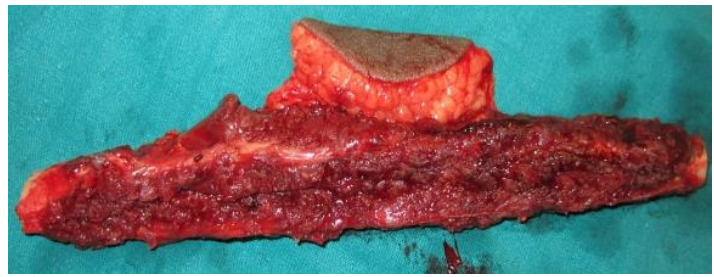

Fig. 5: Free Fibular graft before insetting

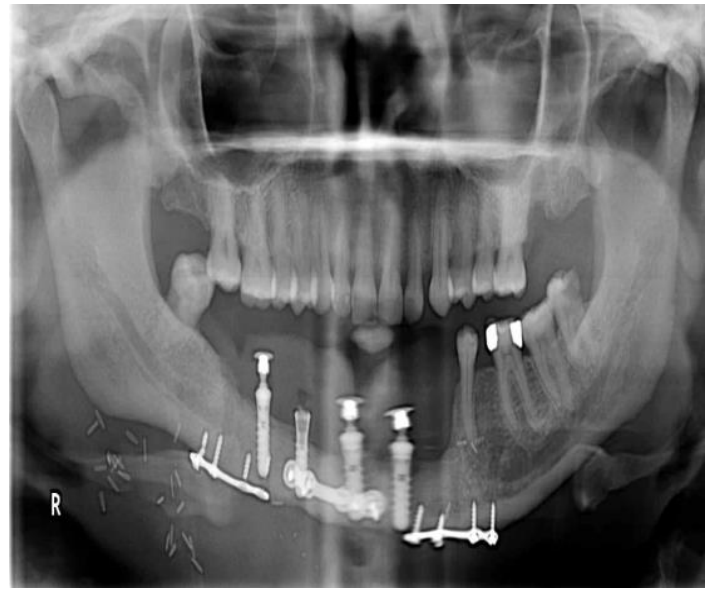

Fig. 6: Post operative orthopantomogram after insetting of the graft

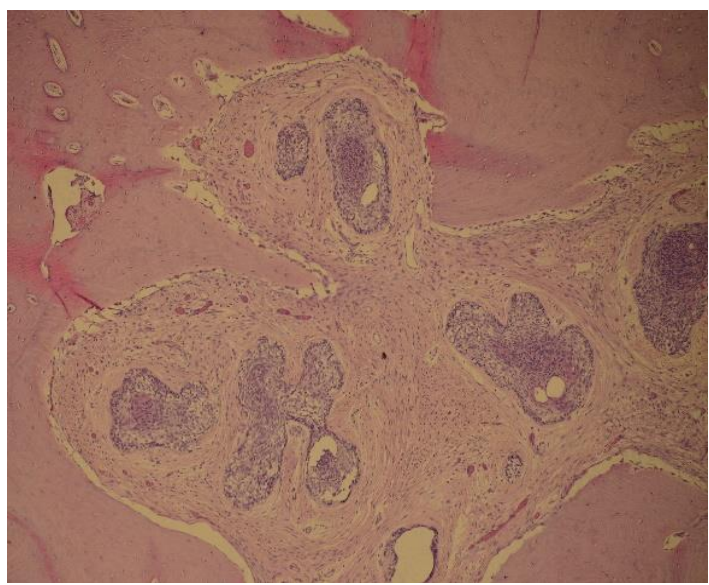

Fig. 7: Histopathology image $(10 \mathrm{x}$ view) 


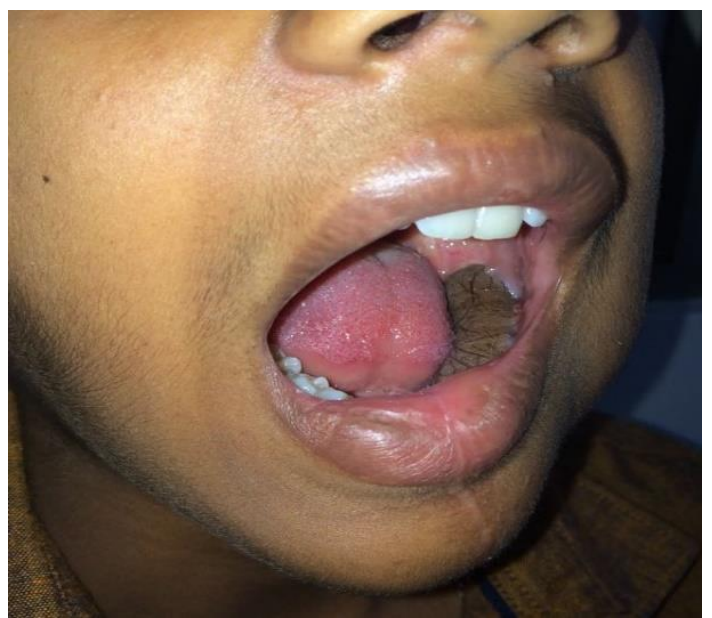

Fig. 8: Postoperative day 21 photograph of oral cavity

\section{Discussion}

Majority of the exclusive mandibular lesions are benign in nature in young and middle aged patients. Differential diagnosis include range of tumors like peripheral fibroma, pyogenic granuloma, peripheral giant cell granuloma, peripheral ameloblastoma etc. Plain X-ray gives clue to the nature of lesion in majority of cases. CT scan of mandible with $3 \mathrm{D}$ reconstruction helps in diagnosing as well as planning the extent of resection. Histopathological evaluation is the single most important criterion to distinguish different types of mandibular lesions including variants of ameloblastoma (benign or malignant), and also ruling out metastases from other primary sites. ${ }^{10}$ Hence should be subjected to biopsy for confirmatory diagnosis. Mandibulectomy (Marginal, Segmental, Hemimandibulectomy), External beam radiation, Curettage are the various treatment options described in literature with varied success rates. Among which, Manibulectomy has been proposed as the best treatment of choice with less recurrence rates. Mandibulectomy can lead to disturbance in appearance, mastication, and speech which severely impair the patients' quality of life. To improve these functional abnormalities, several reconstructive techniques have been described, Free bone flaps have been shown to be superior in gain of bone volume and resistance when compared with other techniques. ${ }^{11,12}$ Radius, scapula, iliac bone and fibular bone are some of the commonly described bone grafts. Irrespective of site of the mandible involved, surgery remains the best available treatment option and with proper reconstruction, good cosmesis can be achieved. Minimum of 1-1.5 cm grossly negative margin is advisable as the bony margin cannot be assessed using frozen section. Extraoral approach remains the access of choice irrespective of whether reconstruction is considered or not. Level $1 \mathrm{~b}, 2$ neck zone exploration needs to be done to isolate recipient vessels when reconstruction is planned. Proper autologous graft, preferably free fibular bone graft provides better cosmesis.

Cases described in our series were of different age groups (in the range of 15 to 46 years). $60 \%$ were females and $40 \%$ were males. In majority of cases, body was involved. Size of the lesion were as small as $1.9 \times 2.6 \mathrm{~cm}$ to as large as $5 \times 4.5 \mathrm{~cm}$. Histolocal types include ameloblastoma and its variants in 8 cases, cementing ossifying fibroma in one case, and angiomatous lesion in another case. Segmental mandibulectomy was done in 9 cases and hemimandibulectomy was done in 1 case. Reconstruction was done using autologous free fibular graft in 8 cases, and using titanium plate in 1 case and no reconstruction was done in 1 case [Table 1]. No major post operative complications were observed. No recurrences were seen till date. Since the infection rate is less when autologous bone grafts are used, in majority of cases, free fibular graft was done. Recurrence chances are less when adequate negative margins are obtained. Aggressive follow up is not required when madibulectomy is done, as the recurrence chances are less when compared to other modalities like curettge, external beam radiation. Though benign in nature, it is aggressive tumor and recurrence rate have been described ranging between $4.5 \%$ and $70-85 \%$ after en bloc resection or conservative therapy respectively, over periods ranging from 5 to 15 years. ${ }^{13,14}$ Hence regular annual long term follow up is required. Blood loss and donor site morbidity were some of the few complications described with bone graft in the literature,${ }^{15}$ which can be managed efficiently. No Case series have been described in literature using titanium plate for reconstruction except for few case reports. ${ }^{16,17}$ Temporary tracheostomy may be required for lesions involving mentum or anterior alveolar region.in case of local recurrence, resurgery for resection of the tumor without disturbing the bone graft and reconstruction with metallic prosthesis have been described. And in case of regional recurrence, resection and reconstruction with various available free flaps have been described. ${ }^{18}$ In case of metastatic disease, chemotherapy comprising cyclophosphamide, cisplatin, doxorubicin and radiotherapy with good response have been reported. ${ }^{19}$ Nodal dissection is advised for ameloblastic carcinoma. ${ }^{20}$ The clinical take home messages are mandatory biopsy, three dimensional reconstruction on imaging, wider bony resection margin and reconstruction preferably with autologous bone graft.

\section{Conclusion}

Surgical resection with adequate negative margin and proper reconstruction, preferably autologous graft determines long term good results in terms of cosmesis and wound related complications, in the process its prognosis.

\section{References}

1. Brazis PW, Miller NR, Lee AG, Holliday MJ. Neuroophthalmologic Aspects of Ameloblastoma. Skull Base Surg 1995;5:233-244.

2. Cusack JW. Report of the amputations of the lower jaw. Dubl Hosp Rec 1827;4:1-38.

3. Cakur B, Caglayan F, Altun O, Miloglu O. Plexiform ameloblastoma. Erciyes Med J 2009;(Suppl 1):S62-67.

4. Madhup R, Srivastava K, Bhatt M, Srivastava S, Singh S, Srivastava AN. Giant ameloblastoma of jaw successfully treated by radiotherapy. Oral Oncol Extra 2006;42:22-25. 
5. Kramer IR, Pindborg JJ, Shear M. 2nd ed. Berlin: SpringerVerlag; 1992. Histological Typing of Odontogenic Tumours. WHO International Histological Classification of Tumours; pp. $11-14$.

6. Paikkatt VJ, Sreedharan S, Kannan VP. Unicystic ameloblastoma of the maxilla: A case report. J Indian Soc Pedod Prev Dent 2007;25:106-110.

7. Gorlin, R. J., Chaudhry, A. P., and Pindborg, J. J.: Odontogenic tumors. Cancer 1961;14:73-101.

8. Hinds, E. C., Pleasants, J. E., and Snyder, P. L.: Management of ameloblastoma. Oral Surg 1954;7:1169-1177.

9. Mamabolo M, Noffke C, Raubenheimer E. Odontogenic tumours manifesting in the first two decades of life in a rural African population sample: a 26 year retrospective analysis. Dentomaxillofac Radiol 2011;40:331-337.

10. Avon SL, McComb J, Clokie C. Ameloblastic Carcinoma: Case Report and Literature Review J Can Dent Assoc 2003;69:573-6a.

11. Zemann W, Feichtinger M, Kowatsch E, Karcher H. Extensive ameloblastoma of the jaws: surgical management and immediate reconstruction using microvascular flaps. Oral Surg Oral Med Oral Pathol Oral Radiol Endod 2007;103:190-196.

12. Peled M, El-Naaj IA, Lipin Y, Ardekian L. The use of free fibular flap for functional mandibular reconstruction. J Oral Maxillofac Surg 2005;63:220-224.

13. Dandriyal R, Gupta A, Pant S, Baweja HH. Surgical management of ameloblastoma: Conservative or radical approach. Natl J Maxillofac Surg 2011;2:22-27.

14. Morgan PR. Odontogenic tumors: a review. Periodontol 2011;57:160-176.
15. Dash H, Little JR, Zaino R, Colao DJ, Chaurushiya P, Schoolwerth AC, O’Neill MJ, Hart JC, Martin GB. Mandibular ameloblastoma treated by bone resection and immediate reconstruction. Braz J Otorhinolaryngol 2008;74:155-157.

16. Montoro JR, Tavares MG, Melo DH, Franco Rde L, MelloFilho FV, Xavier SP, et al. Mandibular ameloblastoma treated by bone resection and immediate reconstruction. Braz J Otorhinolaryngol 2008;74:155-157.

17. Infante-Cossio P, Prats-Golezer V, Gonzalez-Perez LM, Belmonte-Caro R, Martinez-De- Fuentes R, Torres-Carranza $\mathrm{E}$, et al. Treatment of recurrent mandibular ameloblastoma. Exp Ther Med 2013;5:579-583.

18. Juan José Larrañaga. Management Issues in the Treatment of an Ameloblastoma with an Atypical Presentation: Craniomaxillofac Trauma Reconstruction 2015;8:257-261

19. Rui-Na Yang. Mandible ameloblastoma with lung metastasis: a rare case report: Int J Clin Exp Pathol 2015;8(6):6793-6799.

20. P. Satish Kumaran, V. Anuradha, S. Gokkulakrishnan, Lalita Thambiah, Ajay Kumar Jagadish, and G. Satheesh. Ameloblastic carcinoma: A case series. J Pharm Bioallied Sci 2014;6(Suppl 1):S208-S211.

How to cite this article: Kumar HH, Raghunandan GC, Ellur SR, Ramesh RS, Kariappa DK. Surgical resection with autologous microvascular reconstruction of the mandible conferring excellent cosmesis and prognosis in ameloblastoma. Indian J Anat Surg Head Neck Brain 2018;4(4):102-105. 